\title{
Surface Properties of Octacalcium Phosphate Nanocrystals Are Crucial for Their Bioactivities
}

\author{
Lili Fan, Yanmei Zhang, Jiejie Hu, Yuan Fang, Ren Hu,* Wei Shi, Bin Ren, Changjian Lin, \\ and Zhong-Qun Tian
}

Cite This: ACS Omega 2021, 6, 25372-25380

Read Online

ABSTRACT: The fundamental structure-biofunction relationship of calcium phosphates $(\mathrm{CaPs})$ remains unclear despite their clinical successes as important biomaterials. Herein, a series of $\mathrm{CaP}$ coatings with gradual change of topography and crystallinity is constructed by electrochemical deposition, and the roles of the two basic physicochemical properties are scrutinized for further understanding the mechanism behind the superior bioactivities of octacalcium phosphate (OCP). We observe a distinct modulation on cell proliferation on the prepared $\mathrm{CaP}$ coatings for different cells. The magnitude of the modulation seems to depend on the cellular size, and the effect is attributed mainly to the microstructure of the

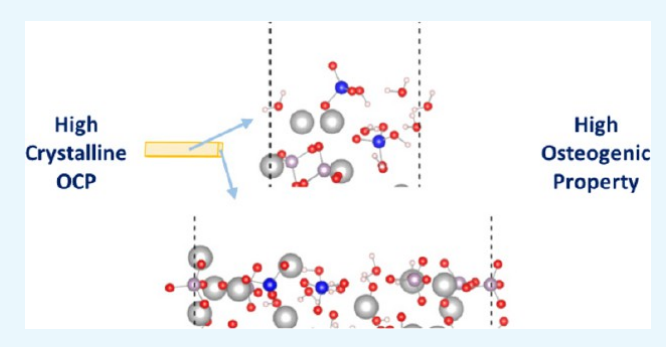
coatings. On the other hand, the crystallinity manifests its significance for the osteogenic property of the OCP coatings. Further transmission electron microscopy analysis and density functional theory calculations reveal a surface rich in $\mathrm{HPO}_{4}{ }^{2-}$ for the highcrystalline OCP nanocrystals. The results highlight that the nanocrystal surface properties of the OCP coatings, including the periodic structure and the $\mathrm{HPO}_{4}{ }^{2-}$ composition, may play significant roles surpassing the ion release effect in determining its osteogenic property, probably via surface spatial and/or chemical recognitions. The present findings shed light on the fundamental understanding of the structure-biofunction relationship for $\mathrm{CaP}$ biomaterials.

\section{INTRODUCTION}

Calcium phosphates (CaPs) being analogues to inorganic components of natural bone are frequently utilized as bone repair and substitute materials. Surface modification by CaPs on biomedical metals, for example, combines the biological properties of the coatings with the mechanical properties of metal substrates and is proved to be highly successful in clinical applications. ${ }^{1-3}$ Despite the clinical successes, the fundamental understandings of the bioactivities of $\mathrm{CaPs}$ are not yet very clear. As the expanding aging population and increasingly younger patients nowadays put higher requirements to the prosthesis, ${ }^{4}$ a more clear and precise understanding of the CaPs' bioactivities, which will contribute to guide and further improve the surface design of the prosthesis, is gaining high interest.

It is well known that physicochemical properties may play significant roles in determining the biological functions of CaPs. Drawing exact structure-biofunction relationships for $\mathrm{CaPs}$ is however much complicated. ${ }^{5} \mathrm{CaPs}$ comprise of different compounds that exhibit quite different morphologies, crystal structures, and compositions. Modulating one parameter may inevitably change a lot of the others. It is, therefore, highly challenging to elicit specific structure-biofunction relationships for $\mathrm{CaP}$ coatings. Not to mention that biological activity itself is a very complex issue.

$\mathrm{CaPs}$ in various formulas and forms have been investigated to achieve adequate performance in applications. ${ }^{6,7}$ Amor- phous calcium phosphate (ACP), dicalcium phosphate dihydrate (DCPD), octacalcium phosphate (OCP), and hydroxyapatite (HA) are four biologically relevant $\mathrm{CaP}$ phases in aqueous solutions. HA is the most thermodynamically stable phase in biological environments and has a crystal structure most resembling that of mature nature bone. ${ }^{8}$ The others are possible precursors for $\mathrm{HA}$. OCP, an acidic $\mathrm{CaP}$, is currently of special interest as it sometimes shows superior bioactivities over synthetic $\mathrm{HA}^{9-11}$ and amorphous carbonated apatite. ${ }^{12}$ It is found that microstructures, ${ }^{13,14}$ stoichiometry, ${ }^{15}$ and other physicochemical characters ${ }^{15-17}$ of OCP can influence greatly its bone-regenerative properties. In mechanism, the osteoconductivity of OCP may be attributed to its conversion process to HA, which involves apatite formation and release/exchange of calcium and phosphate ions with the surroundings. ${ }^{18}$ Despite this knowledge, the superiority of OCP over HA seems to deviate from the bionic understanding of bone biomaterials.

An electrochemical deposition method is a mild technique capable of constructing $\mathrm{CaP}$ coatings on biomedical metals. The technique features high controllability over coating

Received: June 23, 2021

Published: September 20, 2021 
A


B

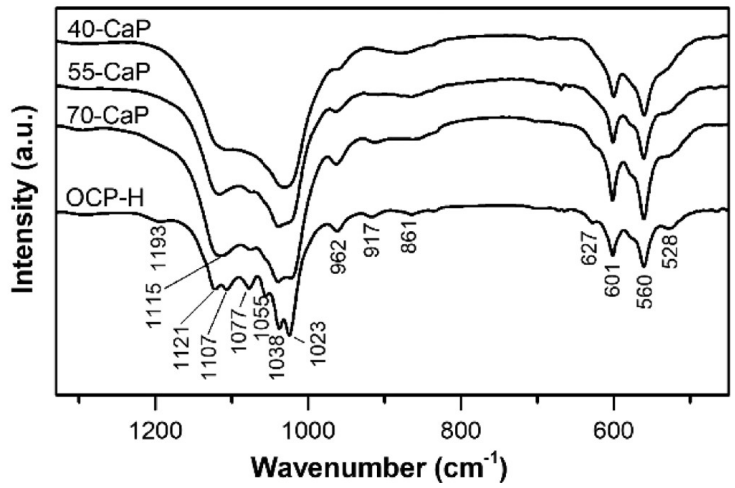

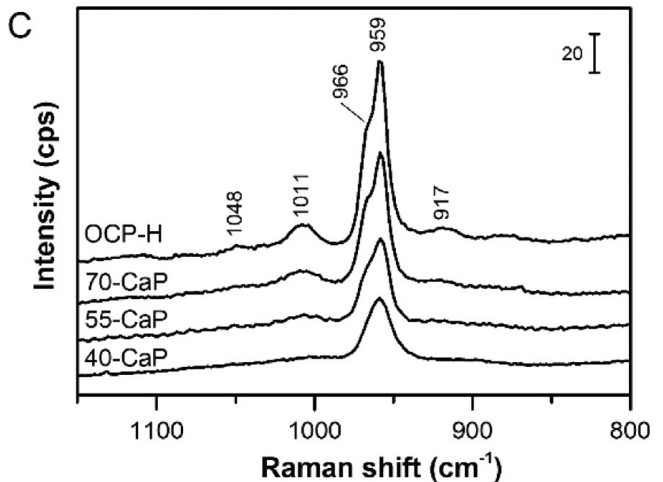

Figure 1. (A) SEM micrographs of the electrochemically deposited 40-CaP, 55-CaP, 70-CaP, and OCP-H coatings at low (upper images) and high (lower images) magnifications. (B) FTIR spectra of the powders scrapped from the coatings. (C) Raman spectra of the corresponding coatings.

properties of morphology, crystal structure, composition, and so on. Herein, we designed and prepared by a galvanostatic method a group of acidic $\mathrm{CaP}$ coatings with progressively changing physicochemical properties on titanium substrates. The biological properties of the coatings were then analyzed by simulated body fluid immersion and cell culture. The relationships between the physicochemical properties and biological properties of the acidic $\mathrm{CaP}$ coatings were then scrutinized based on the structure characterization, property evaluation, and density functional calculations to further elucidate the underlying mechanism.

\section{RESULTS AND DISCUSSION}

Physicochemical Properties of the CaP Coatings. Figure 1A shows the scanning electron microscopy (SEM) micrographs of the four $\mathrm{CaP}$ coatings, namely, 40-CaP, 55$\mathrm{CaP}, 70-\mathrm{CaP}$, and OCP-H. Upper images show uniform coating structures at a lower magnification and a clear change from dense to porous in surface morphology for the coatings from $40-\mathrm{CaP}$ to OCP-H. Lower images show at a higher magnification the morphologic details. The 40-CaP coating displays an amorphous morphology blended with some barely discernable crystal nuclei. The 55-CaP coating consists of epitaxially grown short acicular crystals. The $70-\mathrm{CaP}$ coating is composed of longer crystal belts and presents a similar epitaxial but much loosen surface structure. The OCP-H coating displays a more obvious porous structure compared with the 70-CaP coating. $\mathrm{Ca} / \mathrm{P}$ ratios measured by energy-dispersive $\mathrm{X}$ ray spectroscopy (EDS) were $1.07 \pm 0.02,1.08 \pm 0.01,1.12 \pm$ 0.01 , and $1.13 \pm 0.02$ for the $40-\mathrm{CaP}, 55-\mathrm{CaP}, 70-\mathrm{CaP}$, and OCP-H coatings respectively.
Figure $\mathrm{S} 1$ shows the X-ray diffraction (XRD) patterns of the 40-CaP, 55-CaP, and 70-CaP coatings. The 40-CaP coating exhibits a broad peak at around $26^{\circ}$, and the 55-CaP coating shows a sharper and stronger peak at $26^{\circ}$ and some emerging broad peaks belonging to OCP. While some DCPD impurities were observed for 40-CaP and 55-CaP coatings, all peaks from the 70-CaP coating can be assigned to OCP according to the standard card (PDF\#79-0423). These XRD results combined with the EDS data demonstrate that the $70-\mathrm{CaP}$ coating was mainly composed of calcium-deficient OCP. These three CaP coatings represented an evolution of OCP crystals from ACP, with slow uptake of calcium to the coatings as indicated by a rising $\mathrm{Ca} / \mathrm{P}$ ratio in the $\mathrm{EDS}$ data. The herein observed evolution of calcium-deficient OCP is consistent with the reported in situ observation of calcium-deficient OCP precipitation from an amorphous precursor. ${ }^{19}$ The crystallite sizes of OCP along the $c$ axis, estimated by Scherrer's equation using the full width at half maximum of the (002) diffraction peak, were $19,34,50$, and $45 \mathrm{~nm}$ for the $40-\mathrm{CaP}, 55-\mathrm{CaP}, 70$ $\mathrm{CaP}$, and OCP-H coatings, respectively. The calculated crystallite size increased from $40-\mathrm{CaP}$ to $70-\mathrm{CaP}$ coatings, while those of $70-\mathrm{CaP}$ and $\mathrm{OCP}-\mathrm{H}$ samples were comparable. The observed size changing tendency is consistent with the above SEM analysis.

FTIR spectra of the four $\mathrm{CaP}$ coatings were detected, and the curves are shown in Figure 1B. The $950 \mathrm{~cm}^{-1}$ peak observed for 40-CaP indicates the amorphous nature of the coating. ${ }^{20}$ Peaks at 917,861 , and $528 \mathrm{~cm}^{-1}$ and the peak at $1077 \mathrm{~cm}^{-1}$, which can be assigned to $\mathrm{HPO}_{4}{ }^{2-}$ and to both $\mathrm{HPO}_{4}{ }^{2-}$ and $\mathrm{PO}_{4}{ }^{3-}$ in OCP, respectively, ${ }^{21}$ show a tendency of emerging from $40-\mathrm{CaP}$ to $70-\mathrm{CaP}$. From $40-\mathrm{CaP}$ to OCP-H, 
A
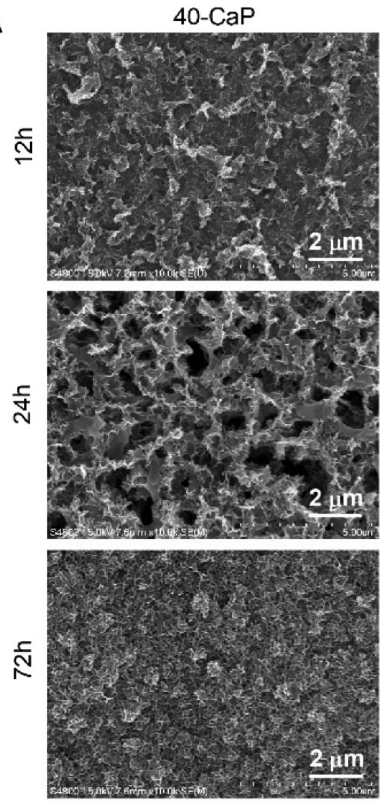

B



$55-\mathrm{CaP}$
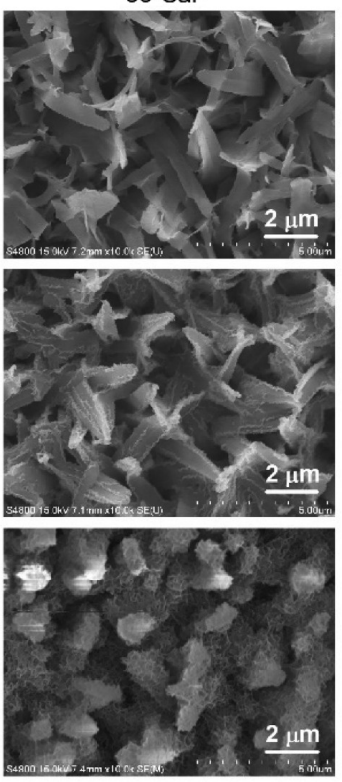

C

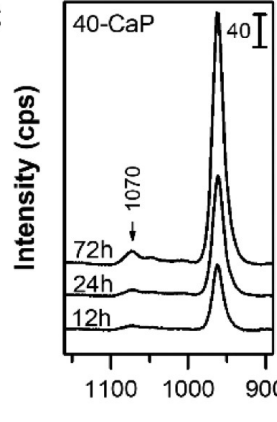

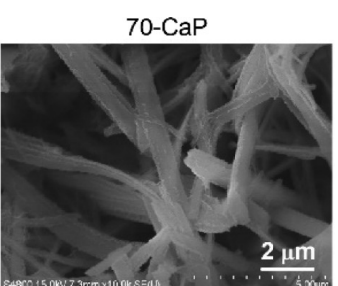
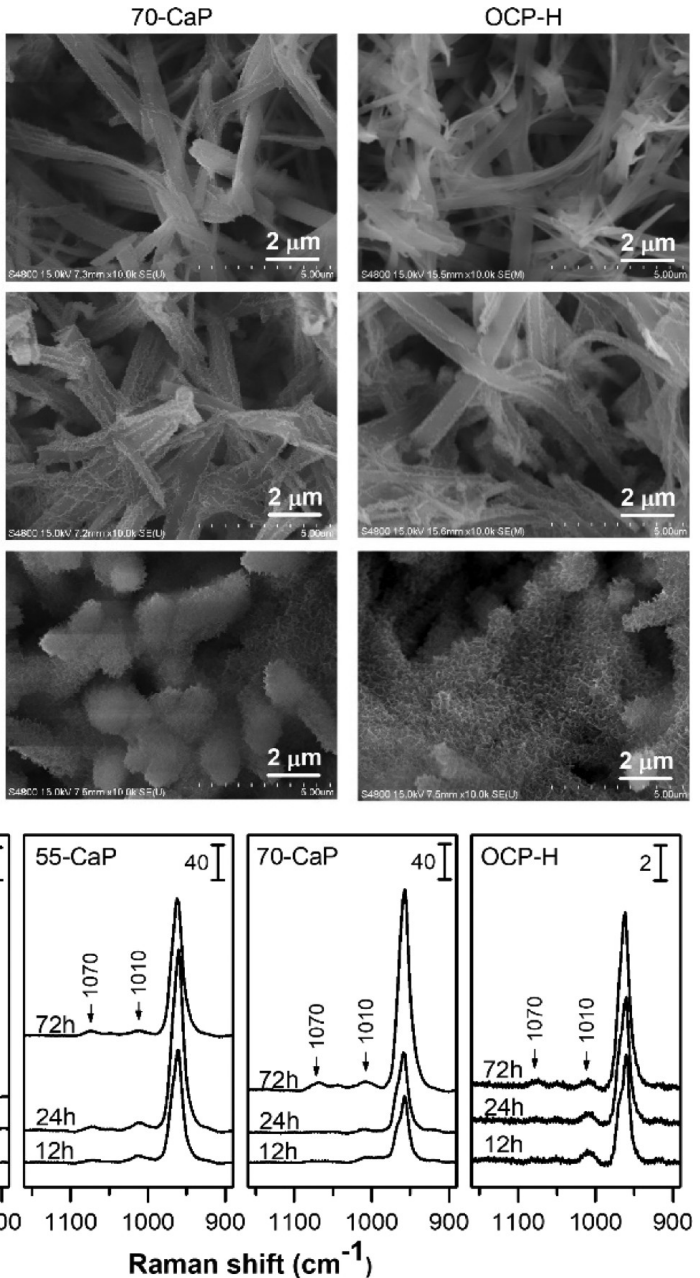

Figure 2. (A) SEM micrographs of four CaP coatings after immersion in simulated body fluid for 12,24 , and 72 h and (B) XRD patterns of the coatings after immersion for $72 \mathrm{~h}$. (C) Raman spectra of the coatings after immersion in simulated body fluid for 12 , 24 , and 72 h.

the peaks at 1115 and $1035 \mathrm{~cm}^{-1}$ show a tendency of splitting to 1121 and $1107 \mathrm{~cm}^{-1}$ peaks and 1038 and $1023 \mathrm{~cm}^{-1}$ peaks, respectively. The observed peak splitting indicated the evolution of higher crystalline OCP structures. ${ }^{13}$ The Raman spectra in Figure $3 \mathrm{~B}$ also show clear strengthening of $\mathrm{HPO}_{4}{ }^{2-}$ peaks (at 1011 and $917 \mathrm{~cm}^{-1}$ ) in the coating. The splitting for the peak at $960 \mathrm{~cm}^{-1}$ from $40-\mathrm{CaP}$ to OCP-H is again consistent with the evolution of high-crystalline OCP crystals from amorphous $\mathrm{CaP}$. No clear FTIR or Raman peaks from DCPD were observed due to its very low content. These FTIR and Raman spectra of the coatings clearly show that the coatings display a progressive increase of the crystallinity from 40-CaP to OCP-H.

The above microscopic and spectroscopic characterizations revealed an evolution of a dense to porous structure accompanied by an incremental crystallinity for the four different $\mathrm{CaP}$ coatings.

Biological Properties of the Acidic CaP Coatings. Simulated Body Fluid Immersion Test. Samples of the four different $\mathrm{CaP}$ coatings immersed in simulated body fluid (SBF) for a duration of $12 \mathrm{~h}, 1$ day, and 3 days were analyzed by SEM, and the results are shown in Figure 2A. Fine precipitations along crystal edges can be observed from the SEM images of 55-CaP, 70-CaP, and OCP-H coatings after immersion for $12 \mathrm{~h}$. Clear dissolution was observed for the 40$\mathrm{CaP}$ coating after immersion for $24 \mathrm{~h}$, whereas the amounts of fine precipitations increased on other coatings. After $72 \mathrm{~h}$ of immersion, all samples were covered by a close layer of fine precipitations. The crystal structures of the four coatings after immersion for $72 \mathrm{~h}$ were analyzed by XRD. The XRD patterns shown in Figure $2 \mathrm{~B}$ demonstrate a characteristic apatitic peak at $26^{\circ}$ and a broad peak at $32^{\circ}$, which are key features of very fine apatitic crystals. ${ }^{22}$ These SEM images and XRD data clearly show a topotactic surface transformation of the prepared coatings toward apatitic structures after SBF immersions.

The Raman spectra of $\mathrm{CaP}$ coatings after immersion for 12, 24, and $72 \mathrm{~h}$ are shown in Figure 2C. A peak at $1070 \mathrm{~cm}^{-1}$ attributed to the B-type carbonate substitution in biological apatite $^{23,24}$ can be clearly observed for 40-CaP and 55-CaP but not for $70-\mathrm{CaP}$ after $12 \mathrm{~h}$ immersion. A peak at $1010 \mathrm{~cm}^{-1}$ attributed to $\mathrm{HPO}_{4}{ }^{2-}$ is well preserved for the 55-CaP, 70-CaP, and OCP-H coatings during the SBF immersion process.

It is known that the transformation of CaPs in SBF takes a dissolution-reprecipitation mechanism. CaPs with a lower crystallinity have a higher dissolution ability and thus could have faster reprecipitation as indicated by earlier emergence of the $1070 \mathrm{~cm}^{-1}$ peak for $40-\mathrm{CaP}$ and $55-\mathrm{CaP}$. This earlier induction of biological apatitic precipitation however does not necessarily indicate a better bioactivity, as shown in below cell culture tests. 
A
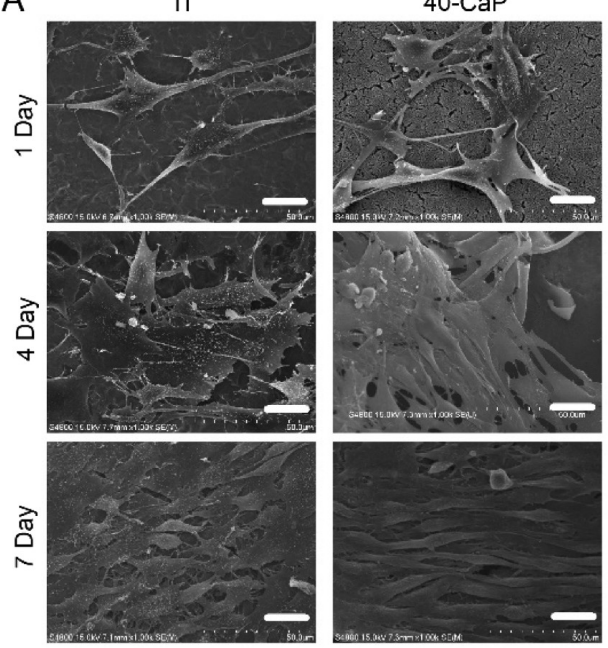

B

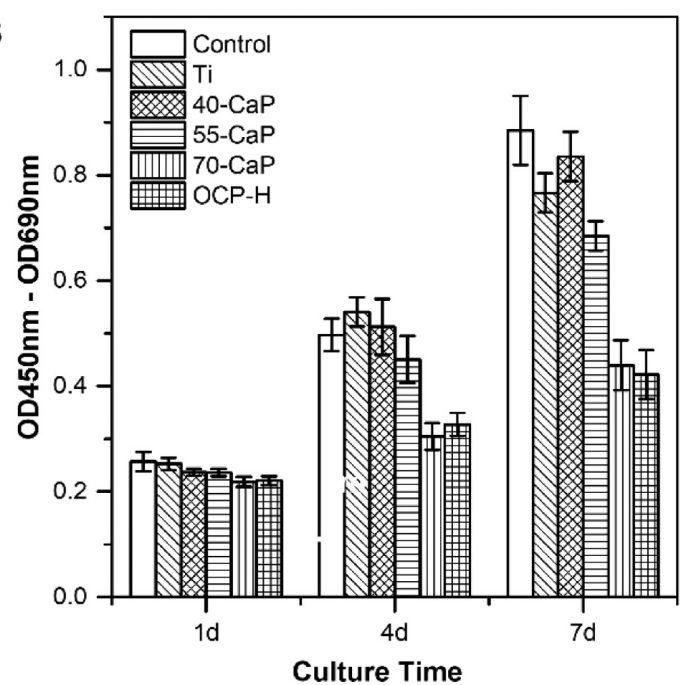

$55-\mathrm{CaP}$


70-CaP
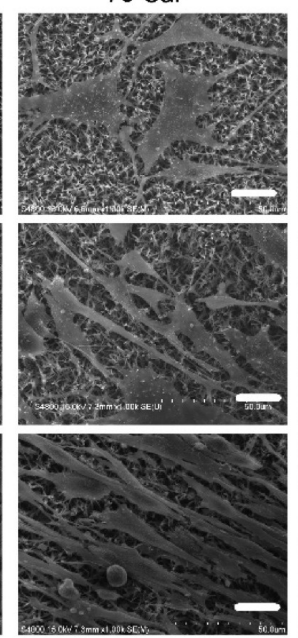

OCP-H

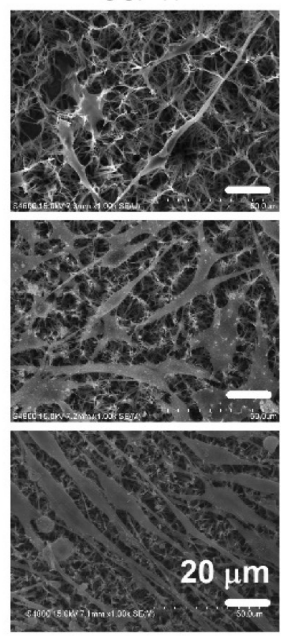

C

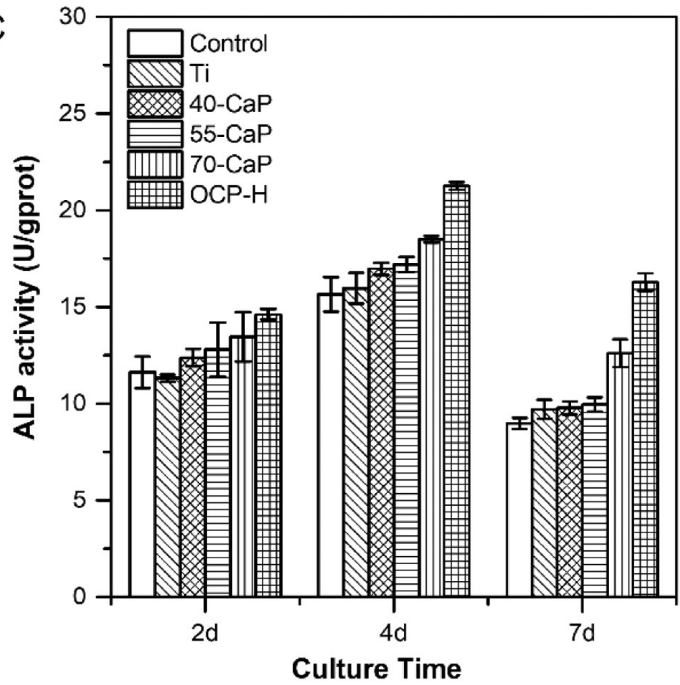

Figure 3. (A) SEM micrographs of MC3T3-E1 cells on the Ti substrate and the prepared CaP coatings after being cultured for 1, 4, and 7 days. (B) WST-1 cell proliferation test and (C) ALP activity test of MC3T3-E1 cells growing on the prepared different CaP coatings.


Figure 4. WST-1 cell proliferation test of different cells, (A) MG-63 cells and B) MEF cells, growing on the prepared CaP coatings.

Cell Culture Test. MC3T3-E1 cells, a preosteoblast cell line, were used to evaluate the intrinsic osteoinductivity of the different CaP coatings. Subcultures of MC3T3-E1 cells were seeded on the samples of $\mathrm{CaP}$ coatings and cultured in a 



Figure 5. TEM image of nanocrystals from the OCP-H coating: (A) one single nanobelt, (B) HRTEM of the area indicated by the black arrow (the inset shows the corresponding selected area electron diffraction pattern), and (C) side view image of the OCP nanobelt shows a layer-by-layer structure. (D) Unit cell of OCP illustrating the positions of (100), (200), (001), and (002). P5, P6, P11, and P12 indicate the four hydrogen phosphate groups. The structure is drawn using parameters reported by Davies et al. ${ }^{26}$

normal maintenance culture medium without any osteogenic additives. The morphology of cells grown on the different coatings, with the $\mathrm{Ti}$ substrate as a control, was analyzed by SEM. It is observed from Figure 3A that MC3T3-E1 cells can grow well on all coatings. After culture for 1 day, the cells attached and spread well on all $\mathrm{CaP}$ coatings. After 7 days of culture, it is observed that cells adapt their morphology to different coating samples, and the cell numbers increase upon culture time. From $40-\mathrm{CaP}$ to OCP-H, the cells tend to exhibit an elongated shape.

The proliferation and differentiation activities of MC3T3-E1 cells grown on the different coatings were analyzed by the WST-1 test and alkaline phosphatase (ALP) activity analysis, respectively, and the results are presented in Figure 3B,C. It is shown that the proliferation of MC3T3-E1 cells is downwardly regulated on coatings from $40-\mathrm{CaP}$ to $70-\mathrm{CaP}$ after being cultured for 4 and 7 days, while no significant differences in proliferation were observed for the 70-CaP and OCP-H coatings. Meanwhile, the ALP activity of MC3T3-E1 cells show a clear tendency to increase from $55-\mathrm{CaP}$ to $\mathrm{CaP}-\mathrm{H}$, while $40-\mathrm{CaP}$ and 55-CaP gave similar levels.

Since cell proliferation and cell differentiation can work both simultaneously and independently, ${ }^{25}$ it is necessary to set controls for deconvolving the herein observed effects on the proliferation or differentiation. We used the close but undifferentiated osteoblast-like MG63 cells and the mouse embryonic fibroblast (MEF) cells as cell controls. The cellular morphology of MG-63 cells on the different CaP coatings cultured for 1 and 7days was detected, and the SEM images (Figure S2) displayed no significant change in cell morphology after 7days culture. The proliferation behaviors of the MG63 cells and the MEF cells on the CaP coatings were tested, and the results are shown in Figure 4. After 7days culture, a clear suppression tendency was observed on the $\mathrm{CaP}$ coatings from 40-CaP to OCP-H for both cells.

The Influence of the Microstructure. It is shown that the coatings from $40-\mathrm{CaP}$ to $70-\mathrm{CaP}$ display morphologies varied from relatively dense to porous in microstructures and the OCP-H coating exhibited the highest porous structure. Supposing that other features are similar for four CaP coatings, there is a good correlation between the coating microstructures and the gradient downregulation of cellular proliferation on coatings, except for the $70-\mathrm{CaP}$ and $\mathrm{OCP}-\mathrm{H}$ samples in the
MC3T3-E1 cell test. The level of the downregulation of proliferation varies for different cells. The level of the downregulation of proliferation for MC3T3-E1 cells and MEF cells is stronger than that for MG-63 cells. Considering that the characteristic size of the microstructure (from submicrometer to $\sim 20 \mu \mathrm{m}$ ) of the $\mathrm{CaP}$ coatings overlaps with the typical cellular size ranges (typical eukaryotic cells have diameters ranging from $10-100 \mu \mathrm{m}$ ), and the former two cell lines derived from mice have smaller sizes than MG-63, which is derived from humans, the match extent between the cellular size and the microstructure size may contribute to the observed different modulation strength.

When compared with the control cells, it seems that the proliferation of MC3T3-E1 on OCP-H is abnormally elevated as compared to that for $70-\mathrm{CaP}$. The phenomenon may have reasons other than microstructure.

The Nanostructure of OCP-H and Its Influence. The solubility of the coatings is an important factor that must be taken into consideration, as released calcium and phosphate ions may contribute to bioactivities. We detected the $\mathrm{Ca}^{2+}$ ion concentration released from $70-\mathrm{CaP}$ and OCP-H coatings soaked in phosphate-buffered saline (PBS) solution using an inductively coupled plasma source mass spectrometer, and the results are shown in Figure S3. The slightly higher $\mathrm{Ca}^{2+}$ ion concentration observed for the 70-CaP coating is related to its less crystallinity compared with the OCP-H coating. The slightly higher $\mathrm{Ca}^{2+}$ might contribute to a better bioactivity, which is however contradictory to the ALP activity results and thus rules out the contribution from released ions. On the other hand, it is noteworthy that the high ALP activity observed for the OCP-H coating is positively related to its crystallinity, which highlights the importance of ordered nanocrystal structures.

TEM experiments were conducted to identify the specific nanocrystal structure of the OCP-H coating, and the results are shown in Figure 5. It is shown that the typical size of the OCP nanobelt in the OCP-H coating is $\sim 200 \mathrm{~nm}$ in width, $\sim 20 \mathrm{~nm}$ in thickness, and of several micrometers long. The size characters of the wide facet of the single OCP nanobelt shown in the HRTEM image (Figure 5B) and the corresponding selected area electron diffraction pattern demonstrate that the exposed wide facet of the nanobelt is parallel to the bc plane, and the OCP nanobelt is preferentially elongated toward the $c$ 
axis. The apatitic layer by hydrated layer structure in the [100] direction ${ }^{26}$ can be observed from the side view of the nanobelt as shown in Figure 5C. Along the [100] direction, both the apatitic layer and the hydrated layer may expose on the wide facet of the OCP nanobelt. Since the apatitic layer and the hydrated layer have different structures and chemistries, they may have different biological properties. It is however difficult to determine which layer is preferentially exposed on the OCP surface by the TEM experiment.

To further clarify the surface structure and chemical content of the OCP nanobelt, we calculated the surface energies of the (100) and (200) planes as representatives of the apatitic layer and hydrated layer, respectively. Those of the (001) and (002) planes, representing the end side of the nanobelt, were also calculated for comparison. The density functional theory (DFT) calculation details are shown in Table S1, and the results are listed in Table 1 . It is shown that (200) has the

Table 1. Surface Energies Calculated for Different Crystal Planes of Octacalcium Phosphate in Contact with Vacuum or Water ${ }^{a}$

$\begin{array}{ccc}\text { OCP crystal plane } & \text { vacuum } & \text { water }(\varepsilon=80) \\ (100) & 81.8(1311) & 28.9(462) \\ (200) & 53.5(858) & 11.8(189) \\ (001) & 58.8(942) & 19.5(312) \\ (002) & 47.4(759) & 15.0(240)\end{array}$

${ }^{a_{T}}$ The values are given in $\mathrm{meV} / \AA^{2}\left(\mathrm{~mJ} / \mathrm{m}^{2}\right)$.

lowest surface energy and is the most stable in water, while the (002) plane has the lowest surface energy in a vacuum. This is consistent with our observations, since the OCP herein were prepared from aqueous electrolyte. The DFT calculations also clearly show that (200) is much more stable than (100) especially in water, suggesting that the hydrated layer is preferentially exposed.

Figure 5D shows the positions of (100), (200), (001), and (002) in a unit cell of OCP. From the (200) crystal face, the feature of the hydrogen phosphate groups in the unit cell of OCP is highly exposed to the crystal surface, which is not the case for (100). The $\mathrm{HPO}_{4}{ }^{2-}$ dominant surface of the OCP nanocrystal may highly contribute to its bioactivities. In nature, $\mathrm{HPO}_{4}{ }^{2-}$ is rich in mature bone minerals and especially on their surfaces. In a recently renewed chemical and structural model, ${ }^{27}$ the mature mineral particles are composed of an internal crystalline core in the form of carbonated HA coated by an amorphous layer in which the $\mathrm{HPO}_{4}{ }^{2-}$ ions are concentrated. It is the hydrated surface rich in $\mathrm{HPO}_{4}{ }^{2-}$ ions rather than the stable crystalline HA structure that plays crucial roles at the mineral-mineral and mineral-biomolecule interfaces in bone tissue. Our findings are consistent with the aforementioned results, in that abundant $\mathrm{HPO}_{4}{ }^{2-}$ on the OCP nanocrystal surface may substantially contribute to the high bioactivities observed for the high-crystalline OCP coatings.

Furthermore, the observed high ALP activity for the highcrystalline OCP-H coating indicates that, in addition to the $\mathrm{HPO}_{4}{ }^{2-}$ content on the surface, ordered nanostructures of the exposed facets, including the end side of the nanobelt, may play important roles as well, presumably by interactions with the molecule of the extracellular matrix or cell membrane. In other words, both the chemical and structural properties of the
OCP nanocrystal surfaces may work synergistically to contribute to the high bioactivity of the OCP-H coatings.

It was previously reported that the introduction of a thin OCP to on a hierarchically structured titania surface remarkably enhanced the MC3T3-E1 cell proliferation and ALP activity of MC3T3-E1 cells. ${ }^{28}$ The herein results emphasis the contribution of nanocrystal surfaces to the previous observations. Furthermore, our results indicate that bioactivities of $\mathrm{CaPs}$ can be significantly modulated by specific $\mathrm{CaP}$ nanocrystal surfaces. Although specific interactions between the nanocrystal surfaces and the cells are not clear at present, we anticipate that the combination of controllable nanocrystal surface construction with the advanced interfacial characterization techniques will help reveal the underlying molecular mechanism in near future.

Other Factors. Other properties such as wettability, ion release, and protein adsorption are capable of directly influencing the localized interaction processes at the biomaterial and biological environment interfaces. The properties are therefore important too. It is however challenging to assess these properties on specific nanocrystal facets by conventional experiments. On the other hand, these properties are derivatives of and highly depend on basic properties such as the microstructure, the nanostructure, and the nanochemistry of the coatings, which in turn highlight the importance of surface structural and compositional properties of nanocrystals.

\section{CONCLUSIONS}

We designed and constructed by an electrochemical deposition method a group of $\mathrm{CaP}$ coatings on titanium substrates. The coatings exhibited gradual change of morphology and crystallinity and provided an ideal coating model for scrutinizing structure-biofunction relationships for the acidic $\mathrm{CaP}$ coatings and understanding the corresponding mechanism. It was clearly shown that the coating topography and crystal grain structures play crucial roles in cellular proliferation and differentiation activities. The $\mathrm{CaP}$ crystal assemblies with size characters at submicro to $10-20$ micrometer scales show a distinct modulation effect on the proliferation of MC3T3-E1 cells, MG-63 cells, and MEF cells, and the magnitude of cellular responses seems to depend on the cellular size. The high ALP activity observed on electrochemically deposited high-crystalline OCP coatings indicates that crystal surface properties including chemical and structural features are crucial in determining bioactivities. Further TEM observations and DFT calculations show that the crystal surface of the OCP belt preferentially takes the hydrated structure that is rich in $\mathrm{HPO}_{4}{ }^{2-}$. This surface composition resembles to that of nature mature bone mineral grains and thus could provide high affinity for interactions that lead to the high bioactivities for high-crystalline OCP coatings. The underlying molecular mechanism is expected to be revealed by the combination of $\mathrm{CaP}$ nanocrystal surface construction with the state-of-the-art interfacial characterization techniques in the future.

\section{EXPERIMENTAL SECTION}

Electrochemical Preparation of CaP Coatings. CaP coatings were deposited on titanium foils in two-electrode galvanostatic mode, with a platinum sheet used as the counter electrode. Four types of $\mathrm{CaP}$ coatings were prepared from two electrolyte recipes. Three of them were prepared from an 
electrolyte containing $0.03 \mathrm{~mol} / \mathrm{L} \mathrm{Ca}\left(\mathrm{NO}_{3}\right)_{2}$ and $0.12 \mathrm{~mol} / \mathrm{L}$ $\mathrm{NaH}_{2} \mathrm{PO}_{4}$, with its $\mathrm{pH}$ adjusted in the range of 3.6-4.2. ${ }^{29} \mathrm{~A}$ cathodic current of $0.5-1.0 \mathrm{~mA} / \mathrm{cm}^{2}$ was applied using an electrochemical workstation (Model 263A Princeton) on the titanium substrate for a duration of $10 \mathrm{~min}$. The coatings prepared at different temperatures of 40,55 , and $70{ }^{\circ} \mathrm{C}$ were denoted as $40-\mathrm{CaP}, 55-\mathrm{CaP}$, and $70-\mathrm{CaP}$, respectively. The fourth type of $\mathrm{CaP}$ coating, denoted as $\mathrm{OCP}-\mathrm{H}$, was prepared from an electrolyte consisting of $0.042 \mathrm{~mol} / \mathrm{L} \mathrm{Ca}\left(\mathrm{NO}_{3}\right)_{2}$ and $0.025 \mathrm{~mol} / \mathrm{L} \mathrm{NH}_{4} \mathrm{H}_{2} \mathrm{PO}_{4}$ with a $\mathrm{pH}$ of 4.35 as previously reported. ${ }^{30}$ The electrodeposition was carried out at a current of $0.5 \mathrm{~mA} / \mathrm{cm}^{2}$ under $70^{\circ} \mathrm{C}$ for $10 \mathrm{~min}$.

Physicochemical Characterization of Coatings. The surface morphology of coatings was detected using a field emission scanning electron microscope (SEM, Hitachi S4800) at an acceleration voltage of $15 \mathrm{KV}$. The crystal phase of samples was measured using an X-ray diffractometer (XRD, PANalytical X'pert $\mathrm{PRO}$ ) with a $\mathrm{Cu}-\mathrm{K} \alpha$ radiation source at 40 $\mathrm{kV}$ and $30 \mathrm{~mA}$. Fourier transform infrared spectroscopy (FTIR, Nicolet IS10 Thermo Scientific) spectra were obtained in the range of $4000-525 \mathrm{~cm}^{-1}$ at a resolution of $4 \mathrm{~cm}^{-1}$ using 32 scans. Raman spectra of $\mathrm{CaP}$ coatings were measured using a confocal Raman microspectroscope (Nanophoton Raman-11) using a $532 \mathrm{~nm}$ laser as the excitation light with a $50 \times$ air microscope objective lens $(\mathrm{NA}=0.45)$. A 600 grooves $/ \mathrm{mm}$ grating spectrograph was used. The laser power was around 2 $\mathrm{mW}$ for Raman measurements. A transmission electron microscope (TEM, FEI Talos F200S, 200KV) was used for the analysis of $\mathrm{CaP}$ nanocrystal structures. The $\mathrm{CaP}$ nanocrystals deposited on titanium foil were scraped off with a surgical blade and dispersed ultrasonically in ethanol solution for $5 \mathrm{~min}$. Subsequently, the dispersion liquid was dropped on copper grids (400 mesh) supported with a carbon film and dried in air, and then, the sample was examined by TEM. The solubility of the coatings was analyzed using an inductively coupled plasma source mass spectrometer (ICP-MS7500CE, American Agilent Technologies) by detecting the concentrations of $\mathrm{Ca}^{2+}$ dissolved in PBS.

Simulated Body Fluid Immersion Test. The CaP coatings were immersed in SBF to evaluate their biomineralization activity. The SBF solution includes $8.035 \mathrm{~g} / \mathrm{L} \mathrm{NaCl}$, $0.355 \mathrm{~g} / \mathrm{L} \mathrm{NaHCO} \mathrm{N}_{3}, 0.225 \mathrm{~g} / \mathrm{L} \mathrm{KCl}, 0.231 \mathrm{~g} / \mathrm{L} \mathrm{K}_{2} \mathrm{HPO}_{4}$. $3 \mathrm{H}_{2} \mathrm{O}, 0.311 \mathrm{~g} / \mathrm{L} \mathrm{MgCl} 2 \cdot 6 \mathrm{H}_{2} \mathrm{O}, 0.072 \mathrm{~g} / \mathrm{L} \mathrm{Na}_{2} \mathrm{SO}_{4}$, and 0.292 $\mathrm{g} / \mathrm{L} \mathrm{CaCl}_{2}$ dissolved in water and buffered at $\mathrm{pH} 7.40$ using Tris and $1 \mathrm{M} \mathrm{HCl}$, referencing Kokubo's formulation. ${ }^{31}$ After immersion in SBF solution for 12,24 , and $72 \mathrm{~h}$ at $37^{\circ} \mathrm{C}$, the samples were removed from the SBF solution, cleaned with deionized water, and air-dried for succeeding analysis.

Cell Culture. The MC3T3-E1 Subclone 14 cell line was purchased from the Cell Library of the Chinese Academy of Sciences. The base medium for this cell line was the alpha minimum essential medium ( $\alpha$-MEM, GIBCO, A1049001) with $10 \%$ fetal bovine serum (FBS, GIBCO, 10270-106). The MG-63 cell line was obtained from BaNa Culture Collection and cultured in DMEM/HIGH GLUCOSE (HyClone SH30243.01) with $10 \%$ FBS. The MEF (CF-1) cell line was purchased from the Cell Library of the Chinese Academy of Sciences. The base medium for this cell line was DMEM/ HIGH GLUCOSE (HyClone SH30243.01) with 10\% FBS. All cells were maintained in a humidified incubator at $37{ }^{\circ} \mathrm{C}$ and $5 \% \mathrm{CO}_{2}$.

Cell Morphology. MC3T3-E1 and MG-63 cells were seeded on different $\mathrm{CaP}$ coatings $(1 \mathrm{~cm} \times 1 \mathrm{~cm}$, the samples were sterilized in $75 \%$ alcohol for $30 \mathrm{~min}$ ) at a density of $5 \times$ $10^{3}$ cells per $\mathrm{cm}^{2}$. The cells were cultured for 1,4 , and 7 days, respectively. Afterward, the samples were washed twice with PBS, fixed with $2.5 \%$ glutaraldehyde for $2 \mathrm{~h}$, dehydrated with different concentrations of alcohol $(30,50,75,90 \%$, and twice of $100 \%$ ) for $15 \mathrm{~min}$, and replaced ultimately with tertiary butanol. Then, the samples were dried in a freeze-dryer (Eyela FDU-1200). Finally, the samples were observed by SEM.

Cell Proliferation. A WST-1 kit (C0036, Byotime) was used to evaluate cell viability. MC3T3-E1, MG-63, and MEF cells were seeded on $\mathrm{CaP}$ coatings at a density of $5 \times 10^{3}$ cells per $\mathrm{cm}^{2}$ using 24-well plates. The cell culture plate was also used as a control. The cells were cultured for 1,4 , and 7 days, respectively. Then, the WST-1 reagent was added to each well (volume ratio of the cell culture medium to the reagent was 10:1) and incubated for $2 \mathrm{~h}$ under a humidified atmosphere with $5 \% \mathrm{CO}_{2}$ at $37^{\circ} \mathrm{C}$. Finally, $100 \mu \mathrm{L}$ of the mixed solution in each well was added to a new 96 -well plate. The optical density of the mixed solution at $450 \mathrm{~nm}$, referenced at $690 \mathrm{~nm}$, was measured using a microplate reader (ELX800, BioTek).

ALP Activity Assay. ALP activity is an important indicator for early osteogenic differentiation of preosteoblasts. The ALP activity of the MC3T3-E1 preosteoblast cells on the prepared coatings was analyzed to evaluate the osteogenic property of the prepared coatings. After incubating for 2, 4, and 7 days, the cells on the samples were washed thrice with PBS and lysed in $0.2 \%$ Triton X-100 per well for $30 \mathrm{~min}$. The ALP activity of the MC3T3-E1 preosteoblast cells was analyzed using an ALP kit (P0321, Beyotime) following instructions. The absorbance of the supernatant at $405 \mathrm{~nm}$ was measured using a microplate reader (ELX800, BioTek). In addition, The ALP activity was normalized to the total protein content.

DFT Calculations. Surface energies were calculated by DFT via the Vienna ab initio simulation package (VASP.5.4.1) with projector augmented wave pseudopotentials. ${ }^{32,33}$ The Perdew-Burke-Ernzerhof functional was employed to describe the exchange-correlation effect. ${ }^{34}$ An implicit solvation model (VASPsol) was used to account for the influence of water. ${ }^{35}$

A plane-wave cutoff of $520 \mathrm{eV}$ and an automated $k$-point mesh $(2 \times 2 \times 1 \Gamma$-centered K-point mesh for $(100)$ and (200); $1 \times 2 \times 1 \Gamma$-centered K-point mesh for (001) and (002)) were used for the surface energy calculations. Surface structures were modeled in a supercell geometry using slabs of (100), (200), (001), and (002) orientations. A vacuum region of $15 \AA$ and a thickness of two structure cycles (220 atoms in total) were used. The upper 55 atoms and lower 55 atoms were fully relaxed, and the remaining 110 atoms in the middle were kept fixed to their bulk positions during relaxations. The convergence criterion for the self-consistent field loop was set to $0.0022 \mathrm{eV}$, and for the structural optimization, it was the default $0.022 \mathrm{eV} / \AA$.

\section{ASSOCIATED CONTENT}

\section{Supporting Information}

The Supporting Information is available free of charge at https://pubs.acs.org/doi/10.1021/acsomega.1c03278.

(Figure S1) XRD patterns of 40-CaP, 55-CaP, and 70$\mathrm{CaP}$ coatings deposited on titanium foils and the OCP standard data (PDF\#79-0423); (Figure S2) SEM micrographs of MG-63 cells on the Ti substrate and the different $\mathrm{CaP}$ coatings after culturing for 1 and 7 
days; (Figure S3) time dependence of $\mathrm{Ca}^{2+}$ ion concentration released from $70-\mathrm{CaP}$ and $\mathrm{OCP}-\mathrm{H}$ coatings soaked in PBS solution; (Table S1) surface energy calculation for different crystal planes of octacalcium phosphate in contact with vacuum or water (PDF)

\section{AUTHOR INFORMATION}

\section{Corresponding Author}

Ren Hu - State Key Laboratory of Physical Chemistry of Solid Surfaces, College of Chemistry and Chemical Engineering, Xiamen University, Xiamen, Fujian 361005, China; 다이.org/0000-0001-6893-529X; Email: renhu@ xmu.edu.cn

\section{Authors}

Lili Fan - State Key Laboratory of Physical Chemistry of Solid Surfaces, College of Chemistry and Chemical Engineering and Department of Biomaterials, College of Materials, Xiamen University, Xiamen, Fujian 361005, China

Yanmei Zhang - State Key Laboratory of Physical Chemistry of Solid Surfaces, College of Chemistry and Chemical Engineering, Xiamen University, Xiamen, Fujian 361005, China

Jiejie Hu - State Key Laboratory of Physical Chemistry of Solid Surfaces, College of Chemistry and Chemical Engineering, Xiamen University, Xiamen, Fujian 361005, China

Yuan Fang - Department of Chemistry, Fudan University, Shanghai 200433, China

Wei Shi - Department of Biomaterials, College of Materials, Xiamen University, Xiamen, Fujian 361005, China; (ㄷ) orcid.org/0000-0002-6718-7952

Bin Ren - State Key Laboratory of Physical Chemistry of Solid Surfaces, College of Chemistry and Chemical Engineering, Xiamen University, Xiamen, Fujian 361005, China; () orcid.org/0000-0002-9821-5864

Changjian Lin - State Key Laboratory of Physical Chemistry of Solid Surfaces, College of Chemistry and Chemical Engineering, Xiamen University, Xiamen, Fujian 361005, China; (1) orcid.org/0000-0003-0032-8420

Zhong-Qun Tian - State Key Laboratory of Physical Chemistry of Solid Surfaces, College of Chemistry and Chemical Engineering, Xiamen University, Xiamen, Fujian 361005, China; ㅇorcid.org/0000-0002-9775-8189

Complete contact information is available at:

https://pubs.acs.org/10.1021/acsomega.1c03278

\section{Author Contributions}

The manuscript was written through contributions of all authors. All authors have given approval to the final version of the manuscript. L.F. and Y.Z. contributed equally.

Notes

The authors declare no competing financial interest.

\section{ACKNOWLEDGMENTS}

This work was financially supported by the Ministry of Science and Technology of China (grant no. 2016YFC1100301) and the Fundamental Research Funds for the Central Universities (20720170031). The authors thank Professor Zhiyuan Jiang and Dr. Fuchun Xu for their assistance in the HRTEM studies. We also thank Professor Qiaoling Huang and Dr. Yun Yang for helpful discussions on cell tests and thank Professor Songyuan Ding for instructions on VASPsol calculations.

\section{REFERENCES}

(1) Duan, K.; Wang, R. Z. Surface modifications of bone implants through wet chemistry. J. Mater. Chem. 2006, 16, 2309-2321.

(2) de Jonge, L. T.; Leeuwenburgh, S. C. G.; Wolke, J. G. C.; Jansen, J. A. Organic-inorganic surface modifications for titanium implant surfaces. Pharm. Res. 2008, 25, 2357-2369.

(3) Paital, S. R.; Dahotre, N. B. Calcium phosphate coatings for bioimplant applications: Materials, performance factors, and methodologies. Mater. Sci. Eng., R 2009, 66, 1-70.

(4) Holzapfel, B. M.; Reichert, J. C.; Schantz, J. T.; Gbureck, U.; Rackwitz, L.; Noth, U.; Jakob, F.; Rudert, M.; Groll, J.; Hutmacher, D. $\mathrm{W}$. How smart do biomaterials need to be? A translational science and clinical point of view. Adv. Drug Deliv. Rev. 2013, 65, 581-603.

(5) Galvan-Chacon, V. P.; Habibovic, P. Deconvoluting the bioactivity of calcium phosphate-based bone graft substitutes: strategies to understand the role of individual material properties. Adv. Healthc. Mater. 2017, 6, 1478.

(6) Habraken, W.; Habibovic, P.; Epple, M.; Bohner, M. Calcium phosphates in biomedical applications: materials for the future? Mater. Today 2016, 19, 69-87.

(7) Eliaz, N.; Metoki, N. Calcium phosphate bioceramics: a review of their history, structure, properties, coating technologies and biomedical applications. Dent. Mater. 2017, 10, 334.

(8) Zhou, H.; Lee, J. Nanoscale hydroxyapatite particles for bone tissue engineering. Acta Biomater. 2011, 7, 2769-2781.

(9) Imaizumi, H.; Sakurai, M.; Kashimoto, O.; Kikawa, T.; Suzuki, O. Comparative study on osteoconductivity by synthetic octacalcium phosphate and sintered hydroxyapatite in rabbit bone marrow. Calcif. Tissue Int. 2006, 78, 45-54.

(10) Fosca, M.; Komlev, V. S.; Fedotov, A. Y.; Caminiti, R.; Rau, J. V. Structural study of octacalcium phosphate bone cement conversion in vitro. ACS Appl. Mater. Interfaces 2012, 4, 6202-6210.

(11) Habibovic, P.; van der Valk, C. M.; van Blitterswijk, C. A.; de Groot, K.; Meijer, G. Influence of octacalcium phosphate coating on osteoinductive properties of biomaterials. J. Mater. Sci. Mater. Med. 2004, 15, 373-380.

(12) Dekker, R. J.; de Bruijn, J. D.; Stigter, M.; Barrere, F.; Layrolle, P.; van Blitterswijk, C. A. Bone tissue engineering on amorphous carbonated apatite and crystalline octacalcium phosphate-coated titanium discs. Biomaterials 2005, 26, 5231-5239.

(13) Honda, Y.; Anada, T.; Kamakura, S.; Morimoto, S.; Kuriyagawa, T.; Suzuki, O. The Effect of Microstructure of Octacalcium Phosphate on the Bone Regenerative Property. Tissue Eng. Part A 2009, 15, 1965-1973.

(14) Murakami, Y.; Honda, Y.; Anada, T.; Shimauchi, H.; Suzuki, O. Comparative study on bone regeneration by synthetic octacalcium phosphate with various granule sizes. Acta Biomater. 2010, 6, 15421548.

(15) Miyatake, N.; Kishimoto, K. N.; Anada, T.; Imaizumi, H.; Itoi, E.; Suzuki, O. Effect of partial hydrolysis of octacalcium phosphate on its osteoconductive characteristics. Biomaterials 2009, 30, 1005-1014.

(16) Anada, T.; Kumagai, T.; Honda, Y.; Masuda, T.; Kamijo, R.; Kamakura, S.; Yoshihara, N.; Kuriyagawa, T.; Shimauchi, H.; Suzuki, O. Dose-dependent osteogenic effect of octacalcium phosphate on mouse bone marrow stromal cells. Tissue Eng. Part A 2008, 14, 965978

(17) Sai, Y.; Shiwaku, Y.; Anada, T.; Tsuchiya, K.; Takahashi, T.; Suzuki, O. Capacity of octacalcium phosphate to promote osteoblastic differentiation toward osteocytes in vitro. Acta Biomater. 2018, 69, $362-371$

(18) Suzuki, O. Octacalcium phosphate: Osteoconductivity and crystal chemistry. Acta Biomater. 2010, 6, 3379-3387.

(19) Habraken, W.; Tao, J. H.; Brylka, L. J.; Friedrich, H.; Bertinetti, L.; Schenk, A. S.; Verch, A.; Dmitrovic, V.; Bomans, P. H. H.; Frederik, P. M.; Laven, J.; van der Schoot, P.; Aichmayer, B.; de With, G.; DeYoreo, J. J.; Sommerdijk, N. Ion-association complexes unite 
classical and non-classical theories for the biomimetic nucleation of calcium phosphate. Nat. Commun. 2013, 4, 1507.

(20) Combes, C.; Rey, C. Amorphous calcium phosphates: synthesis, properties and uses in biomaterials. Acta Biomater. 2010, 6, 3362-3378.

(21) Fowler, B. O.; Markovic, M.; Brown, W. E. Octacalcium phosphate. 3. Infrared and Raman vibrational spectra. Chem. Mater. 1993, 5, 1417-1423.

(22) Gu, Y. W.; Tay, B. Y.; Lim, C. S.; Yong, M. S. Biomimetic deposition of apatite coating on surface-modified NiTi alloy. Biomaterials 2005, 26, 6916-6923.

(23) Khan, A. F.; Awais, M.; Khan, A. S.; Tabassum, S.; Chaudhry, A. A.; Rehman, I. U. Raman spectroscopy of natural bone and synthetic apatites. Appl. Spectrosc. Rev. 2013, 48, 329-355.

(24) Penel, G.; Leroy, G.; Bres, C. R. E. MicroRaman spectral study of the $\mathrm{PO} 4$ and $\mathrm{CO} 3$ vibrational modes in synthetic and biological apatites. Calcif. Tissue Int. 1998, 63, 475-481.

(25) Brown, G.; Hughes, P. J.; Michell, R. H. Cell differentiation and proliferation-simultaneous but independent? Exp. Cell Res. 2003, 291, 282-288.

(26) Davies, E.; Duer, M. J.; Ashbrook, S. E.; Griffin, J. M. Applications of NMR crystallography to problems in biomineralization: refinement of the crystal structure and P-31 solid-state NMR spectral assignment of octacalcium phosphate. J. Am. Chem. Soc. 2012, 134, 12508-12515.

(27) Von Euw, S.; Wang, Y.; Laurent, G.; Drouet, C.; Babonneau, F.; Nassif, N.; Azais, T. Bone mineral: new insights into its chemical composition. Sci. Rep. 2019, 9, 8456.

(28) Jiang, P. L.; Liang, J. H.; Song, R.; Zhang, Y. M.; Ren, L.; Zhang, L. H.; Tang, P. F.; Lin, C. J. Effect of octacalcium-phosphatemodified micro/nanostructured titania surfaces on osteoblast response. ACS Appl. Mater. Interfaces 2015, 7, 14384-14396.

(29) Fan, L. L.; Zhang, Y. M.; Hu, R.; Lin, C. J.; Shi, W.; Tian, Z. Q. Strontium substituted octacalcium phosphate coatings by electrochemical deposition and their dose-dependent bioactivities. Mater. Lett. 2020, 272, 4.

(30) Lai, Y. K.; Lin, C. J.; Wang, H.; Huang, J. Y.; Zhuang, H. F.; Sun, L. Superhydrophilic-superhydrophobic micropattern on $\mathrm{TiO} 2$ nanotube films by photocatalytic lithography. Electrochem. Commun. 2008, 10, 387-391.

(31) Kokubo, T.; Takadama, H. How useful is SBF in predicting in vivo bone bioactivity? Biomaterials 2006, 27, 2907-2915.

(32) Kresse, G.; Furthmüller, J. Efficient iterative schemes for ab initio total-energy calculations using a plane-wave basis set. Phys. Rev. B 1996, 54, 11169-11186.

(33) Kresse, G.; Joubert, D. From ultrasoft pseudopotentials to the projector augmented-wave method. Phys. Rev. B 1999, 59, 17581775.

(34) Hammer, B.; Hansen, L. B.; Nørskov, J. K. Improved adsorption energetics within density-functional theory using revised Perdew-Burke-Ernzerhof functionals. Phys. Rev. B 1999, 59, 7413.

(35) Mathew, K.; Kolluru, V. C.; Mula, S.; Steinmann, S. N.; Hennig, R. G. Implicit self-consistent electrolyte model in plane-wave densityfunctional theory. J. Chem. Phys. 2019, 151, 234101. 